\title{
Real-time Defect Detection of Die Cast Rotor in Induction Motor Based on Circular Flux Sensing Coils
}

\begin{abstract}
The die cast rotor bars in squirrel cage induction motors (SCIMs) are easily subjected to porosity or other defects in production, which considerably affects the motors' reliability and efficiency in operation. Planar flux sensing coils have been investigated for the defect detection of SCIM rotor. However, these types of sensors cannot accurately evaluate the severity of porosity or broken bar. This study develops a novel instrument to inspect and quantitatively analyze the rotor quality of SCIM. The sensor consists of the electromagnetic flux sensing coils directly from a SCIM stator. By injecting a DC voltage at phases A and B of the sensor, the induced voltage signal is generated from phase $C$. A quantitative fault indicator (QFI) is constructed on the basis of the instrument voltage output. The variation trend of the QFI with respect to fault severity is investigated by establishing a theoretical sensor model. Experimental results indicate that the proposed method can accurately detect the porosity and broken bar and evaluate their severities for the die cast rotor. The developed solution can be easily implemented with low cost and computational complexity, which can achieve real-time inspection of SCIM rotor in the production line.
\end{abstract}

Index Terms-SCIM, rotor defect detection, fault diagnosis, real-time edge computing, circular flux sensing coils, QFI.

\section{NOMENCLATURE}

$Q_{R}$

$u_{\text {abce, }} u_{1-Q_{R}}(\mathrm{~V})$

$i_{\text {abce }}, i_{1-Q_{R}}(\mathrm{~A})$

$\varphi_{\text {abce, }} \varphi_{1-Q_{R}}(\mathrm{~Wb})$

$r_{\text {srbe }}(\Omega)$

$L_{S S, r r, e}(\mathrm{H})$

$M_{x y}(\mathrm{H})$

$R(\Omega)$

$\varphi(\mathrm{Wb})$

$\alpha_{N}(\mathrm{~cm})$

$\alpha_{Q}\left({ }^{\circ}\right)$

$i_{R, k}(\mathrm{~A})$

$I_{B, k}(\mathrm{~A})$

$S$

$\alpha_{S}\left({ }^{\circ}\right)$

$\alpha_{R}\left({ }^{\circ}\right)$

$I_{B}(\mathrm{~A})$

$I_{R}(\mathrm{~A})$

$I_{B, k}(\mathrm{~A})$

$I_{R, k}(\mathrm{~A})$

$\mu_{0}(\mathrm{H} / \mathrm{m})$

$\delta, \delta^{\prime \prime}(\mathrm{mm})$

$N_{S}$

$\varepsilon S$

$\omega_{R}(\mathrm{rad} / \mathrm{s})$

$l_{\mathrm{Fe}}(\mathrm{cm})$
$D(\mathrm{~cm})$

$B_{S}(\mathrm{~T})$

$\psi_{R S}(\mathrm{~Wb})$

$\psi_{R R}(\mathrm{~Wb})$

$\psi_{R_{\sigma} G}(\mathrm{~Wb})$

$\psi_{R}(\mathrm{~Wb})$

$L_{\sigma R}(\mathrm{H})$

$L_{\sigma B}(\mathrm{H})$

$M_{R}(\mathrm{H})$

$R_{B}(\Omega)$

$S\left(\mathrm{~m}^{2}\right)$

$U_{S, C}(\mathrm{~V})$

$T$ (s)

$T_{1}$ (s)

$T_{2}$ (s)

Ind(a.u.)

Hea (V)

$\operatorname{Fau}(\mathrm{V})$
The diameter of the rotor.

The fundamental wave at the stator coordinates

The flux excited by stator on the kth grid region.

The flux excited by rotor on the kth grid region.

Geometric magnetic flux leakage.

The total flux.

Magnetic leakage self-induction of rotor end ring

Magnetic leakage self-induction of rotor bar.

The mutual inductance between rotor and stator.

The rotor bar resistance.

The cross-sectional area of resistance.

The induced voltage generated in phase $\mathrm{C}$.

The total data processing time.

The data acquisition time.

The data calculation time.

The indicator used for comparison of methods.

The amplitude of healthy rotor signal.

The amplitude of faulty rotor signal.

\section{INTRODUCTION}

$\mathrm{T}$ Transport electrification is a way forward to decarbonize the transport sector worldwide while reducing greenhouse gas emissions, which is a significant content in international and governmental agendas. Electric vehicles (EVs) are developing rapidly as a market and as a research topic. Driving motor is a key component in an EV. At present, squirrel cage induction motor (SCIM) and permanent magnet synchronous motor (PMSM) are the widely used motors in EVs. PMSMs have high efficiency and power density [1]. However, the permanent magnets can be subjected to demagnetizations due to high temperature and intense vibration, and this condition will further affect motor performance and even cause vehicle safety [2]. Moreover, the production of rare earth materials that are used in magnets is influenced by policies, and this situation affects the stable manufacturing of the PMSMs. In contrast to the PMSM, the SCIM, without using rare earth materials, is more reliable, easier to manufacture, and simpler in structure [3]. Thus, the SCIMs have been increasingly used as the driving motors in EVs.

The efficiency of SCIM is the key factor that affects the driving range of an EV. In addition, a high-efficient motor produces less heat and lower temperature during working, and this condition further reduces the fault probability and increases the service life. Literature indicated that the rotor loss accounts for $20 \%-25 \%$ of total motor loss [4]. Reducing rotor loss is a crucial aspect to improve motor efficiency.

Die cast is a commonly used technology to produce the SCIM rotor [5]. Typical materials for die cast bars are aluminum and copper. Compared with the aluminum rotor, the 
copper rotor has lower loss since the conductivity of copper is higher. Therefore, the copper rotors can improve the motor efficiency along with the overall EV efficiency. For example, Tesla's Model X EV uses the SCIMs with the die cast copper rotors.

Although the die cast rotors have considerable advantages in performance, the manufacturing process is more complex and difficult to control [6]. The challenges are as follows: 1) the die cast temperatures of the copper and aluminum rotors are approximately $1100{ }^{\circ} \mathrm{C}$ and $700{ }^{\circ} \mathrm{C}$, respectively. High temperature is a great challenge to the mold of the rotor and affects die cast accuracy [7].2) High temperature induces rapid oxidation. The copper will be oxidized rapidly in the melting process when the temperature exceeds $1200^{\circ} \mathrm{C}$, which induces porosities and other defects, resulting in poor cast quality. 3) The long and narrow rotor slots make the cast process more difficult due to the poor fluidity of the melted metal, which induces bubbles and sand holes. Therefore, the quality inspection of die cast rotors is necessary to guarantee the motor quality and provide a guide for improving the manufacturing process.

Many defect detection methods have been developed and applied for the assessment of rotor quality in both online and offline scenarios. On-line monitoring is mainly for the motors under working conditions [8-11]. The related methods for signal analysis and processing are shown in [12-14]. However, the off-line rotor inspection in the production line before rotor assembly is of more significance in guarantying motor quality and reducing failures in operation. At present, the quality of die cast rotor can be inspected using technologies including mass weighing, ultrasonic detection, and electromagnetic detection. For example, Clark et al. proposed a method to evaluate the health of rotor bar by using magnetic field analysis [15]. Varghese et al. proposed a method that uses the electromagnetic coil sensor to detect the rotor fault by analyzing the induced voltage [16]. Ceban et al. proposed a new index for the detection of rotor faults in induction motors using the external magnetic field analysis [17]. Hosseinpoor et al. proposed an industrial implementation of a virtual sensor in the process of fault detection of an induction motor [18]. Dias et al. used a Hall effect sensor installed between two stator slots of a SCIM to detect the rotor broken fault [19]. Nemec et al. proposed a method for the inspection of electric and magnetic asymmetries of rotor cage in a SCIM [20]. Jeong et al. used the electromagnetic sensor for rotor quality inspection [21].

The above-mentioned methods can distinguish different kinds of rotor faults including porosity and broken bar in specific circumstances. However, accurate quantitative analysis of these faults has not been realized yet, and the sensors are also complicated to design and implement. Thus, this study aims to design a novel sensing solution that can quantitatively analyze the severity of porosity and broken bar in the production line with real-time capability. The sensor is adopted from the stator windings of a SCIM, namely, by injecting a DC voltage at phases $\mathrm{A}$ and $\mathrm{B}$ of the instrument, the induced voltage signal is generated from phase C. Such an instrument simplifies the detection requirement compared with the traditional detection methods that need specially designed sensors. Furthermore, a SCIM model has been developed from the aspects of magnetic and electric fields in this paper, and the theoretical analysis of the sensor detection method has been carried out to derive the characteristics of the signals generated by the rotor in healthy and different faulty states. Accordingly, a quantitative fault indicator $(\mathrm{QFI})$ is proposed to evaluate the severity of the detected fault with low computational complexity. The proposed sensing and defect detection solution has high accuracy and efficiency. It is also easy to implement in reality which makes it a promising solution in the rotor production industry. With the development of sensing technology, electronics, and artificial intelligence for industrial automation, more and more techniques will be applied to real-time edge computing. The designed instrument shows great potential to improve the efficiency and accuracy of real-time inspection of SCIM rotor in the production line.

The rest of the article is structured as follows. Section II models the SCIM stator windings from the aspects of magnetic field and electric field. Section III introduces the theoretical analysis and derivation of the proposed method, and the experimental procedure. Section IV introduces the experimental setup. Section V introduces the results of the comparative experiments. Section VI presents the discussion and prospects. Section VII draws the conclusions.

\section{Electromagnetic Modeling of SCIM}

In this study, a SCIM stator is transformed into an electromagnetic sensor by injecting a DC voltage at phases A and $\mathrm{B}$. An induced voltage signal is then generated from phase C. To clearly introduce the principle of induced voltage generation, the three-phase SCIM model is established to deduce the QFI for fault detection and evaluation.

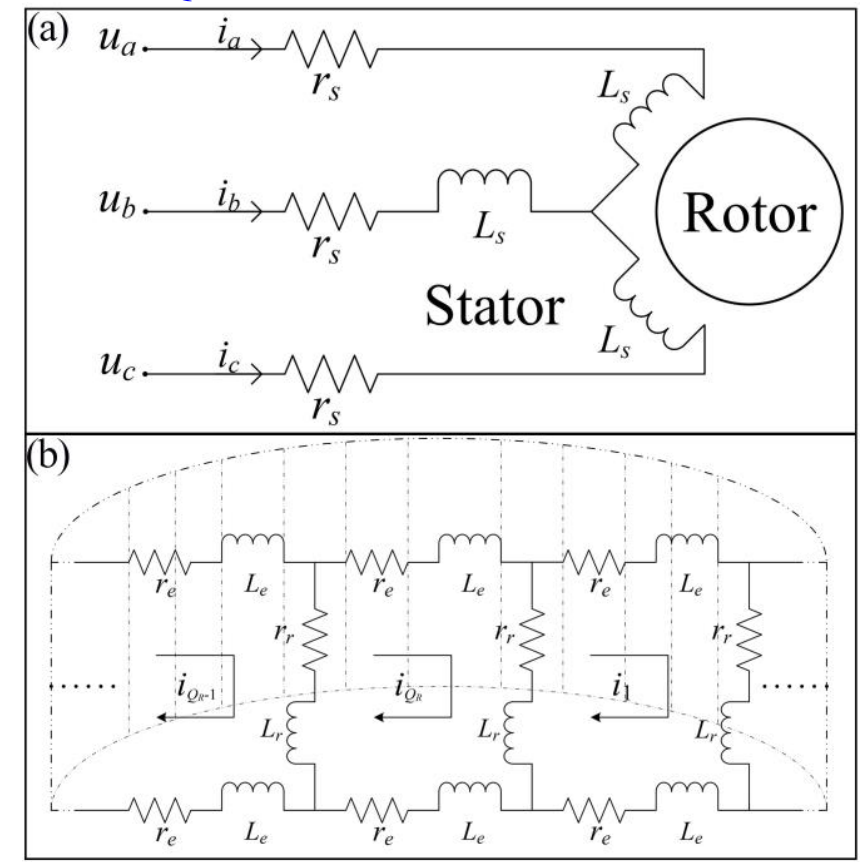

Fig. 1. (a) SCIM modeland (b) internal circuit structure of rotor.

A SCIM model and the internal circuit structure of rotor are shown in Figs. 1(a) and 1(b), respectively. The state equation of SCIM can be obtained from Fig. 1(a)-(b). The matrix equations of the voltage and current vectors in the stator are expressed as [22] 


$$
\left\{\begin{array}{l}
U=\left[u_{S}, u_{r}\right]^{\mathrm{T}} \\
I=\left[I_{S}, I_{r}\right]^{\mathrm{T}}
\end{array}\right.
$$

where

$$
\left\{\begin{array}{l}
u_{S}=\left[u_{a}, u_{b}, u_{c}\right] \\
u_{r}=\left[u_{1}, u_{2}, \cdots, u_{Q_{R}}, u_{e}\right] \\
I_{S}=\left[i_{a}, i_{b}, i_{c}\right] \\
I_{r}=\left[i_{1}, i_{2}, \cdots, i_{Q_{R}}, i_{e}\right]
\end{array}\right.
$$

where $u_{a}, u_{b}$, and $u_{c}$ are the phase voltages; $u_{1}$ to $u_{n}$ are the voltages of rotor bars; $Q_{R}$ is the number of rotor bars; $u_{e}$ is the voltage of the rotor end ring; and the definitions of the currents are similar to those of the voltages. The SCIM voltage equation is expressed as

$$
U=R I+p \varphi
$$

where $R$ is the resistance matrix, $p$ is the differentiation operator, and $\varphi$ is the flux matrix. By substituting (1) and (2) into (3), the multi-loop model of stator voltage of a healthy SCIM can be obtained as [23]

$$
\left[\begin{array}{c}
u_{a} \\
u_{b} \\
u_{c} \\
u_{1} \\
u_{2} \\
\vdots \\
u_{Q_{R}} \\
u_{e}
\end{array}\right]=\left[\begin{array}{cccccccc}
r_{S} & 0 & 0 & 0 & 0 & 0 & \cdots & 0 \\
0 & r_{S} & 0 & 0 & 0 & 0 & \cdots & 0 \\
0 & 0 & r_{S} & 0 & 0 & 0 & \cdots & 0 \\
0 & 0 & 0 & r_{r} & -r_{b} & 0 & \cdots & -r_{b} \\
0 & 0 & 0 & r_{b} & r_{r} & -r_{b} & \cdots & 0 \\
\vdots & \vdots & \vdots & \vdots & \vdots & \vdots & \ddots & \vdots \\
0 & 0 & 0 & -r_{b} & 0 & 0 & \cdots & r_{r} \\
0 & 0 & 0 & r_{e} & r_{e} & r_{e} & \cdots & r_{e}
\end{array}\right]\left[\begin{array}{c}
i_{a} \\
i_{b} \\
i_{c} \\
i_{1} \\
i_{2} \\
\vdots \\
i_{Q_{R}} \\
i_{e}
\end{array}\right]+p\left[\begin{array}{c}
\varphi_{a} \\
\varphi_{b} \\
\varphi_{c} \\
\varphi_{1} \\
\varphi_{2} \\
\vdots \\
\varphi_{Q_{R}} \\
\varphi_{e}
\end{array}\right]
$$

where

$$
\left[\begin{array}{c}
\varphi_{a} \\
\varphi_{b} \\
\varphi_{c} \\
\varphi_{1} \\
\varphi_{2} \\
\vdots \\
\varphi_{Q_{R}} \\
\varphi_{e}
\end{array}\right]=\left[\begin{array}{ccccccccc}
L_{S S} & M_{a b} & M_{a c} & M_{a 1} & M_{a 2} & M_{a 3} & \cdots & M_{a Q_{R}} & 0 \\
M_{b a} & L_{S S} & M_{b c} & M_{b 1} & M_{b 2} & M_{b 3} & \cdots & M_{b Q_{R}} & 0 \\
M_{c a} & M_{c b} & L_{S S} & M_{c 1} & M_{c 2} & M_{c 3} & \cdots & M_{c Q_{R}} & 0 \\
M_{1 a} & M_{1 b} & M_{1 c} & L_{r} & M_{12} & M_{13} & \cdots & M_{Q_{R}} & L_{e} \\
M_{2 a} & M_{2 b} & M_{2 c} & M_{21} & L_{r r} & M_{23} & \cdots & M_{2 Q_{R}} & L_{e} \\
\vdots & \vdots & \vdots & \vdots & \vdots & \vdots & \ddots & \vdots & \vdots \\
M_{Q_{q} a} & M_{Q_{k} b} & M_{Q_{k} c} & M_{Q_{R} 1} & M_{Q_{R} 2} & M_{Q_{R} 3} & \cdots & L_{r r} & L_{e} \\
0 & 0 & 0 & L_{e} & L_{e} & L_{c} & \cdots & L_{e} & Q_{R} L_{e}
\end{array}\right] \cdot\left[\begin{array}{c}
i_{a} \\
i_{b} \\
i_{c} \\
i_{1} \\
i_{2} \\
\vdots \\
i_{Q_{R}} \\
i_{c}
\end{array}\right]
$$

where $u_{x}, i_{x}$, and $\varphi_{x}(x=a, b, c)$ are the voltage, current, and flux of the equivalent winding of the stator phase, respectively. $u_{y}$, $i_{y}$, and $\varphi_{y}\left(y=1,2, \ldots, Q_{R}\right)$ are the voltage, current, and flux of the $y$ rotor loop, respectively. $u_{e}, i_{e}$, and $\varphi_{e}$ are the voltage, current, and flux of the rotor end ring, respectively. $r_{S}, r_{r}, r_{b}$, and $r_{e}$ are the resistance of stator phase winding, rotor loop, rotor bar, and rotor end ring in each segment, respectively. $L_{S s}, L_{r r}$, and $L_{e}$ are the self-inductions of stator phase winding, rotor loop, and rotor end ring in each segment, respectively. $M_{x y}$ and $M_{y x}$ are the mutual inductances between the stator phase winding and rotor loop.

The annular rotor grid for a healthy SCIM is illustrated in Fig. 2, in which each slot width $\alpha_{N}$ represents a loop. An electric angle deviation $\alpha_{Q}$ will exist among each grid due to the symmetrical structure. $i_{R, k}$ is the rotor end ring current at the node of the $k$ th grid region. $i_{B, k}$ and $i_{B, k-1}$ are the rotor bar current at the nodes of the $k$ th and $(k-1)$ th grid region, respectively.

The relationship between $\alpha_{S}$ and $\alpha_{R}$ can be expressed as [24]

$$
\alpha_{S}(t)=\alpha_{R}+\frac{(1-s)}{p} t
$$

where $s$ is the slip rate, $\alpha_{s}$ is the mechanical angular variable in the stator coordinate system, $\alpha_{R}$ is the mechanical angular variable in the rotor coordinate system.

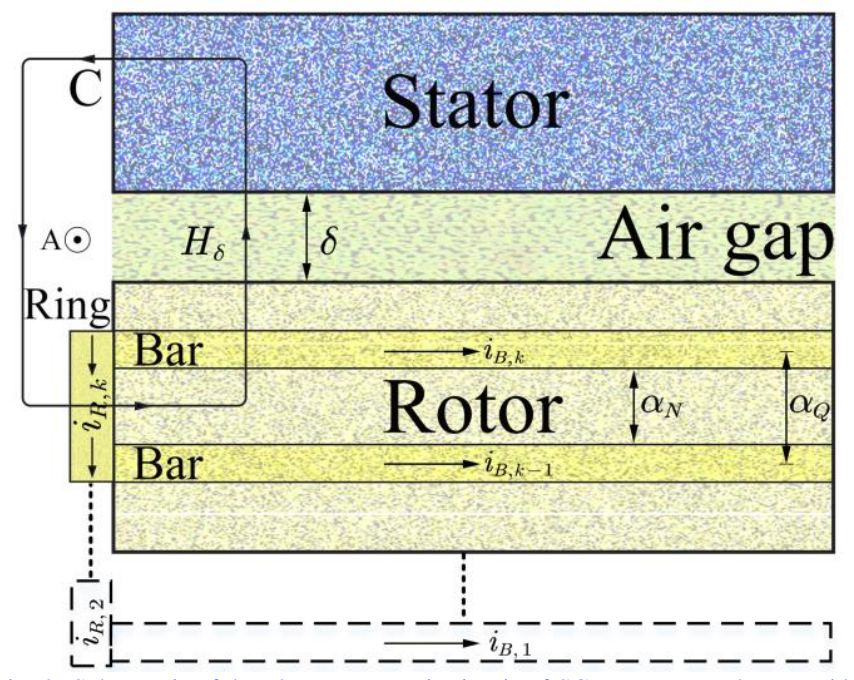

Fig. 2. Schematic of the electromagnetic circuit of SCIM stator and rotor grid.

A simplified rotor model that includes rotor currents and rotor leakage flux paths can be obtained according to [25]. In the case of only considering the constant phase difference between the rotor bar and the rotor end ring, $I_{R, k}$ and $I_{B, k}$ can be expressed as

$$
\left\{\begin{array}{l}
I_{R, k}=I_{R} \times e^{-j(k-1) p \alpha_{Q}} \\
I_{B, k}=I_{B} \times e^{-j\left(k-\frac{1}{2}\right) p \alpha_{Q}}
\end{array}\right.
$$

According to Fig. 2 and the Kirchhoff equation, the current between the rotor bar and rotor end ring at the node of the $k$ th grid region can be obtained as

$$
I_{B, k}=I_{R, k+1}-I_{R, k}
$$

where $I_{B}$ is the value of the rotor bar current, $I_{R}$ is the value of the rotor end ring current. $I_{B, k}$ is the rotor bar current at the node of the $k$ th grid region. $I_{R, k}$ and $I_{R, k+1}$ are the rotor end ring current at the nodes of the $k$ th and $(k+1)$ th grid region, respectively. Substituting (7) into (8) yields the following expression:

$$
I_{B}=I_{R} \times\left(e^{j \frac{1}{2} p \alpha_{Q}}-e^{-j \frac{1}{2} p \alpha_{Q}}\right)=j \times 2 \sin \left(\frac{1}{2} p \alpha_{Q}\right) I_{R}
$$

On the basis of [26] and (6), the fundamental wave of the magnetic field generated at the stator coordinates and the fundamental wave of the air gap magnetic field are shown as

$$
\left\{\begin{array}{l}
B_{S}\left(\alpha_{R}, t\right)=\frac{3 \sqrt{2} \mu_{0} \varepsilon_{S} N_{S} I_{B}}{\delta^{\prime \prime} \times \pi \times p} \times \cos \left(p \alpha_{R}-\omega_{R} t-\varphi_{S}\right) \\
B_{\delta}(t)=\frac{\mu_{0}}{\delta^{\prime \prime}} i_{R, k}(t)
\end{array}\right.
$$

where $\mu_{0}$ is the air gap permeability, $\delta$ and $\delta^{\prime \prime}$ are the ideal and practical air gap widths, respectively, $N_{S}$ is the number of series turns of equivalent sinusoidal winding of stator phase winding, and $\varepsilon_{S}$ is the stator winding factor. $\omega_{R}$ is the electrical frequency of the rotor. $\varphi_{s}$ is the stator initial angle.

The flux excited by stator on the $k$ th grid region is written as 


$$
\begin{aligned}
\psi_{R S}(t) & =\int_{A} B_{S}\left(\alpha_{R}, t\right) d\left(\frac{l_{F e} D}{2} \alpha_{R}\right) \\
& =\frac{3 \sqrt{2} D l_{F e} \mu_{0} N_{S}}{p Q_{R} \delta^{\prime \prime}} I_{B} \cos \left[\omega_{R} t+\varphi_{S}-p(k-1) \alpha_{Q}\right]
\end{aligned}
$$

where $l_{F e}$ is the effective length of core and $D$ is the diameter of the rotor, the values of which can be determined when the SCIM is determined.

The magnetic field excited by the rotor on the $k$ th grid region of the excitation of the flux is written as

$$
\psi_{R R}(t)=\iint_{C} B_{\delta} d\left(\frac{l_{F e} D}{2} \alpha_{R}\right)=\frac{\pi D l_{F e}}{Q_{R} \delta^{\prime \prime}} \times i_{R, k}(t)
$$

Geometric magnetic flux leakage due to rotor current can be expressed as

$$
\psi_{R_{\sigma} G}(t)=2 L_{\sigma R} i_{R, k}(t)+L_{\sigma S}\left[i_{B, k}(t)-i_{B, k-1}(t)\right]
$$

where $L_{\sigma R}$ is magnetic leakage self-induction of rotor end ring, and $L_{\sigma B}$ is the magnetic leakage self-induction of rotor bar. Thus, the total flux generated on the $k$ th grid region can be expressed as

$$
\psi_{R}(t)=\psi_{R S}(t)+\psi_{R R}(t)+\psi_{R_{\sigma} G}(t)
$$

The induced voltage $U_{S}$ generated in the stator winding grid can be obtained as

$$
U_{S}=R_{S} I_{S}+j \omega_{S} L_{S S} I_{S}+j \omega_{S} M_{R} I_{R}
$$

where $M_{R}$ is the mutual inductance between rotor loop and the stator phase winding. The proposed QFI will be derived from (15) in the next section.

\section{Designed InSTRument For Quality InSPECTION OF ROTOR BAR IN SCIM}

In this section, the proposed sensing and inspection solution including the designed instrument and proposed algorithm for rotor quality inspection are introduced.

\section{A. Mechanical Structure Manipulation of the Designed Instrument}
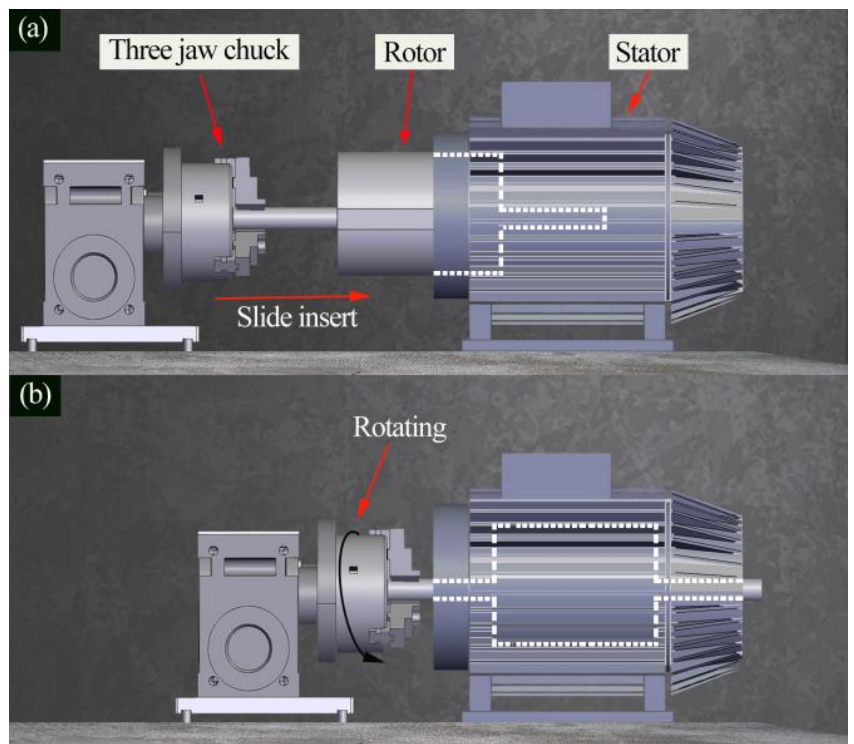

Fig. 3. Illustration of rotor quality inspection in two steps: (a) step 1, (b) step 2.

The mechanical structure of the designed instrument is illustrated in Fig. 3. In this study, a SCIM stator is directly used as an electromagnetic sensor. The stator and the rotor to be tested are placed coaxially. In an automatic factory, the rotor quality inspection can be realized through two steps: 1) a mechanical device or an industrial robot arm picks the rotor through a three-jaw chuck and inserts it into the rotor cavity, as shown in Fig. 3(a). 2) The rotor is driven to spin at constant speed by using an external driving motor, as shown in Fig. 3(b). The two steps can be easily implemented using industry automation technology, which will improve the efficiency of rotor quality inspection.

\section{B. Electrical Structure of the Designed Sensor}

The stator with three-phase windings is used as a sensor, as shown in Fig. 4. A constant DC voltage is injected into the phases of A and B. When the rotor spins within the cavity of the stator, an induced voltage $U_{S, C}$ will be generated in the winding of phase C. The $U_{S, C}$ signal is processed to obtain the QFI for rotor quality inspection.

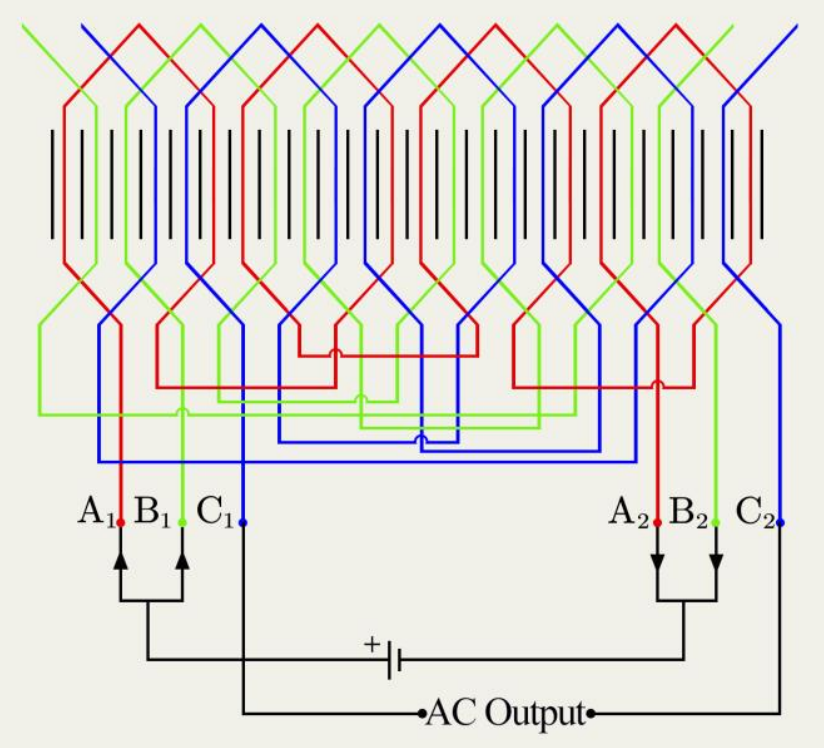

Fig. 4. Wiring diagram of the sensor based on SCIM stator winding.

Subsequently, the proposed QFI is derived from the induced voltage $U_{S, C}$ based on two assumptions: 1) no power input at phase $\mathrm{C}$, and 2) the phase angle difference between $I_{B}$ and $I_{R}$ satisfies $I_{B} \ll<I_{R}$. The flux equation generated on the $k$ th grid region in (11) and (13) can be simplified as

$$
\left\{\begin{array}{l}
\psi_{R S}(t)=0 \\
\psi_{R R}(t)=2 L_{\sigma R} i_{R, k}(t) \\
\psi_{R_{G} G}(t)=\frac{2 \pi \mu_{0} D l_{F e}}{Q_{R} \delta} \times i_{R, k}(t)
\end{array}\right.
$$

The total flux in (15) can be simplified as

$$
\psi_{R}(t)=\left(\frac{2 \pi \mu_{0} D l_{F e}}{Q_{R} \delta^{\prime \prime}}+\frac{\pi D l_{F e}}{Q_{R} \delta^{\prime \prime}}\right) \times i_{R, k}(t)
$$

The $U_{S, C}$ can be finally obtained as

$$
U_{S, C}=\frac{\pi D l_{F e}\left(2 \mu_{0}+1\right)}{2 \times Q_{R} \times \delta^{\prime \prime} \times \sin \left(\frac{1}{2} p \alpha_{Q}\right)} \times I_{B}
$$

The proposed QFI can evaluate the severity of the porosity and broken bar, which will be introduced in the following two subsections. 


\section{Evaluation of the Porosity in SCIM Rotor}

The assumption is that the $k$ th bar of the rotor has a porosity fault, and the resistance of this rotor bar and its Ohm's law can be written as

$$
\left\{\begin{array}{l}
R_{B}=\rho \frac{L}{S} \\
I_{B}=\frac{U_{B}}{R_{B}}
\end{array}\right.
$$

where $R_{B}$ is the rotor bar resistance, $\rho$ is the coefficient of resistance, $S$ is the cross-sectional area of current through a resistance, $L$ is the length of current through a resistance, and $U_{B}$ is the rotor bar voltage.

Substituting (19) into (18) yields the following expression

$$
U_{S, C}=\frac{\pi D l_{F e}\left(2 \mu_{0}+1\right) U_{B}}{2 \times Q_{R} \times \rho \times L \times \delta^{\prime \prime} \times \sin \left(\frac{1}{2} p \alpha_{Q}\right)} \times S
$$

As shown in (20), when a porosity fault occurs in the $k$ th rotor bar, the cross-sectional area of this bar $S$ decreases, and $U_{S, C}$ decreases accordingly. The porosity fault will destroy the structural symmetry of rotors and the current balance among the rotor bars. Thus, the magnitude decrease of $U_{S, C}$ is obvious to indicate the severity of the porosity fault. The parameters of the above equations are determined in the stages of motor design and manufacturing. In this study, the key parameters related to sensor design and signal processing are provided by consulting the motor manufacturer.

\section{Evaluation of the Broken Bar in SCIM Rotor}

When a rotor bar is subjected to a porosity fault, the current can still flow across the bar. In this subsection, the variation in $U_{S, C}$ is investigated when the rotor bar is totally broken. If the $j$ th rotor bar is broken, then the $j$ th current loop will be merged into the $(j+1)$ th current loop. When a rotor bar is broken, $Q_{R}$ will decrease. In addition, Ref. [27] indicated that the current of the bar adjacent to the broken bar will increase about two to three times, that is, $I_{S}$ increases. Accordingly, $U_{S, C}$ will increase according to (19).

Subsequently, the severity of broken bar is analyzed. The different broken volumes in a broken bar will affect the internal magnetic field and electromagnetic force of the SCIM. The increase in the broken volume will cause the asymmetry of the structure, and then, the electromagnetic force is increased. Such a result will reduce the rotor magnetic field intensity and increase the rotor voltage imbalance. The rotor bar voltage $U_{B}$ and $U_{S, C}$ will then decrease according to (20). In summary, a rotor that has a larger volume of broken bar will have a lower value of $U_{S, C}$. As a result, the QFI can be constructed from the $U_{S, C}$ signal.

\section{E. Flowchart of the Proposed Method}

The flowchart of the proposed method is shown in Fig. 5 for better illustration. First, the voltage signal $U_{S, C}$ is sampled, and its spectrum is calculated using fast Fourier transform. The amplitude of the fundamental frequency of $U_{S, C}$ is used as the QFI and denoted as $P U_{S, C}$. Next, the porosity and broken bar are detected by comparing the $P U_{S, C}$ of the fault SCIM with that of the healthy one. The threshold of the $P U_{S, C}$ of the healthy motor, which is denoted as Th, is obtained from the benchmark experiment from a healthy motor.

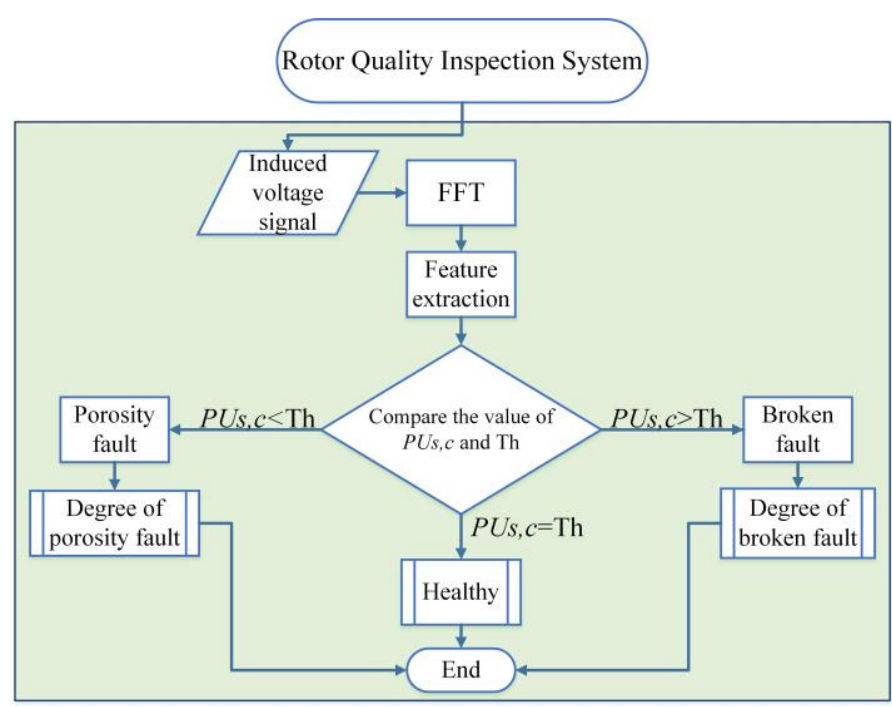

Fig. 5. Flowchart of the proposed method.

\section{EXPERIMENTAL SETUP}

In this section, the designed instrument and experimental setup are introduced.

\section{A. Experimental Setup}

The experimental setup is shown in Fig. 6. As introduced in Section III.A, the designed instrument for rotor quality inspection is based on a stator of a SCIM with the parameters shown in Table I.

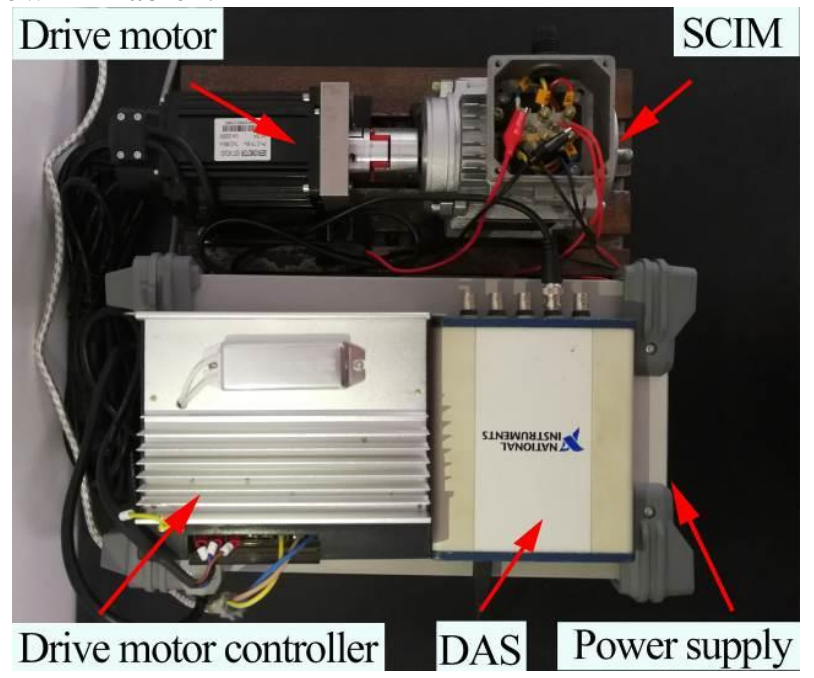

Fig. 6. Experimentalsetup.

The test rotor is driven by an external drive motor through a mechanical coupling as shown in Fig. 6. The rotation speed can be set by a servo motor controller. A DC power supply with a voltage of $30 \mathrm{~V}$ is used to energize the stator windings in phases $\mathrm{A}$ and $\mathrm{B}$ according to the wiring diagram in Fig. 4. According to the electromagnetic induction principle, a voltage signal will be generated at phase $\mathrm{C}$. The open-circuit induced signal is captured using a data acquisition system (DAS, USB-4432, NI Inc.) with the sampling frequency $F_{S}$ of $4 \mathrm{kHz}$. 
TABLE I

PARAMETERS OF THE SCIM

\begin{tabular}{cccc}
\hline \hline $\begin{array}{c}\text { Rated } \\
\text { voltage }(\mathrm{V})\end{array}$ & $\begin{array}{c}\text { Rated } \\
\text { current }(\mathrm{A})\end{array}$ & $\begin{array}{c}\text { Rated } \\
\text { power }(\mathrm{W})\end{array}$ & $\begin{array}{c}\text { No. of } \\
\text { phases }\end{array}$ \\
\hline 380 & 0.39 & 90 & 3 \\
\hline \hline
\end{tabular}

\section{B. Experimental Rotors}

An industrial SCIM rotor generally has multiple bars. The currents among the rotor bars are difficult to measure and analyze accurately. Thus, apart from a practical SCIM rotor, another two simplified rotors are manufactured to better observe the phenomenon and to validate the performance of the proposed method. The rotor framework is constructed using 3D printing technology as shown in Fig. 7 to improve the manufacturing efficiency. The manufacturing process of the rotor models is introduced as follows. The rotor consists of a rotor framework including a rotor shaft and a rotor core, and the rotor windings (squirrel cage). Considering that the electrical conductivity of copper is better than that of aluminum, the copper bar is used to construct the rotor models. The copper bars are connected by the copper wires using tin soldering. The rotor shaft and rotor core are printed using a 3D printer. The rotor bars with different conditions including healthy, porosity, and broken are inserted into the slots of the rotor framework to simulate the different healthy or faulty rotor types.

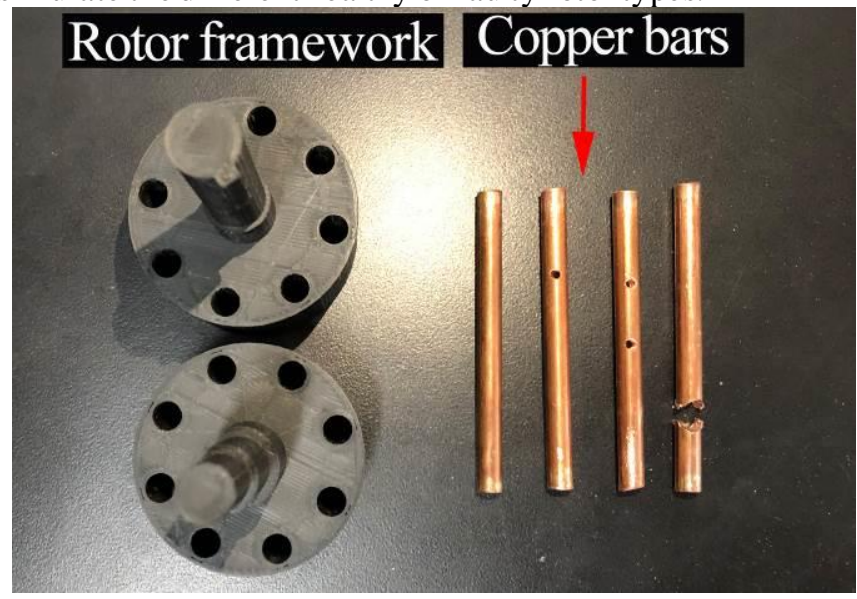

Fig. 7. Illustration of the lab-manufactured rotor.

Finally, five simplified rotors are manufactured as shown in Fig. 8. The rotors include a 2-bar healthy rotor, two 2-bar rotors with low and high porosity density, a 4-bar healthy rotor, and a 4-bar rotor with broken bar. The rotors with porosity fault are configured by drilling holes on a rotor bar. The holes will not penetrate the rotor bar, that is, current can still flow through this rotor bar. The broken bar is configured by drilling a hole, and the dimension of the hole is larger than that of the bar. Specifically, the bar is totally broken into two segments, and the current cannot flow through it. The rotor model consisting of two bars cannot form a current path when the bar is broken. As a result, the broken bar experiment is conducted on a 4-bar rotor. Different kinds of faults are also set on several practical SCIM rotors with 22 bars, as shown in Fig. 9. These rotors are disassembled from the commercial motors which have been quality inspection before delivery. Hence, the disassembled rotors are healthy. In practice, for a newly developed motor type, the initial healthy state of the rotor can be determined by using the existing methods and then the Th value can be obtained. After that, a more detailed quantitative analysis can be conducted by using the proposed method.

The conditions of the rotors include healthy, porosity with different levels, and broken bar with different levels. The configuration of fault levels of the 22-bar rotor is similar to that of the 2- and 4-bar rotors. Therefore, a total of 12 rotors with three types are used in the experiments, which are summarized in Table II.

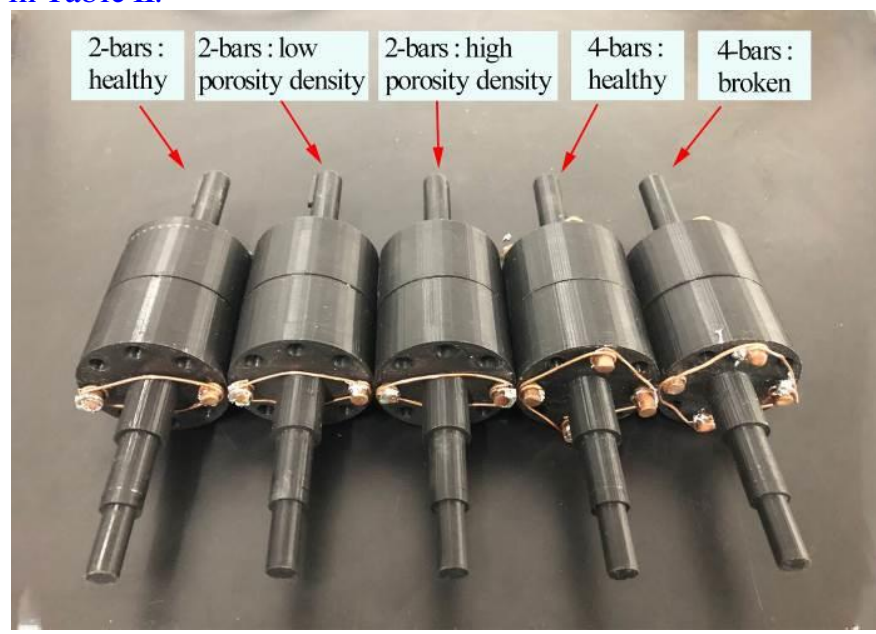

Fig. 8. Manufactured rotors with different fault types and degrees.

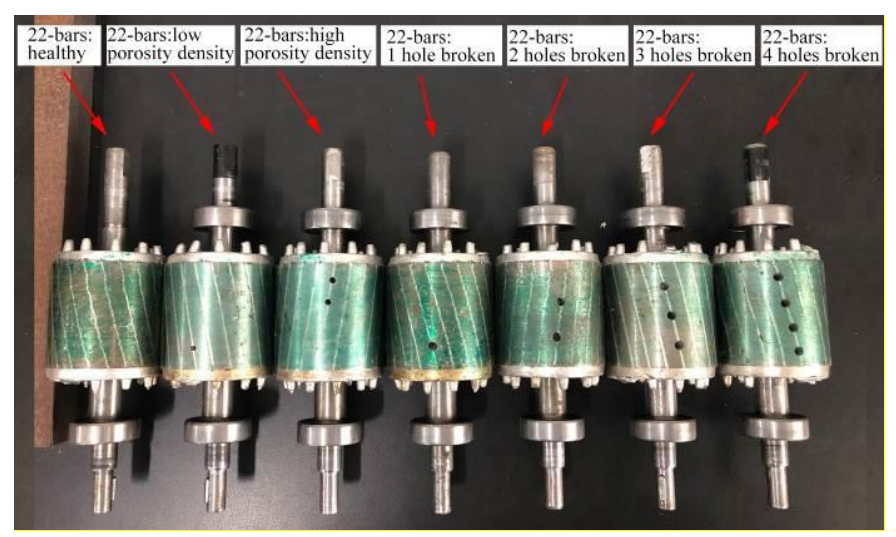

Fig. 9. Practical SCIM rotors with different fault types and degrees.

TABLE II

THE NUMBER OF ROTORS USED IN THE EXPERIMENTS

\begin{tabular}{cccc}
\hline \hline Rotor types & 2-barRotors & 4-bar Rotors & 22-bar Rotors \\
\hline Health & 1 & 1 & 1 \\
\hline Porosity & $\begin{array}{c}\text { 2 (low and high } \\
\text { porosity } \\
\text { density) }\end{array}$ & 0 & $\begin{array}{c}\text { 2 (low and high } \\
\text { porosity density) }\end{array}$ \\
\hline Broken bar & 0 & $\begin{array}{c}\text { 1 (1 hole } \\
\text { broken })\end{array}$ & $\begin{array}{c}4 \text { (1-4 holes } \\
\text { broken) }\end{array}$ \\
\hline \hline
\end{tabular}

\section{EXPERIMENTAL RESULTS}

In this section, the effectiveness of the proposed method for the evaluation of rotor porosity and broken bar is validated. Three kinds of rotors including 2, 4, and 22 bars are tested, respectively. A higher rotation speed can generate a $U_{S, C}$ signal with a higher amplitude. But much high voltage will exceed the measurement range of the DAS. Hence, the rotation speed is set below or equal to $3000 \mathrm{rpm}$. In addition, a comparative method is used to validate the superiority of the proposed method. 


\section{A. Evaluation of Porosity in a 2-bar Rotor}

First, the threshold value of the induced voltage $U_{S, C}$ of a healthy rotor is determined. The driving motor is configured to rotate at speeds of 1600,2000 , and $2400 \mathrm{rpm}$. The acquired $U_{S, C}$ signals and their corresponding amplitude spectra are shown in Fig. 10. As observed, the $U_{S, C}$ signal is a quasi-periodic signal due to the symmetry of the three-phase stator windings. In this study, the fundamental frequencies of these signals are analyzed. As the noise interference is not obvious in the waveform, no extra preprocessing is applied. The signal amplitude of $U_{S, C}$ increases with the increase in rotation speed. The magnitude of the fundamental frequency $P U_{S, C}$ also increases with the rotation speed, as shown in Figs. 10(b), $10(\mathrm{~d})$, and $10(\mathrm{f})$. The benchmark rotation speed is set as 2400 $\mathrm{rpm}$ and the threshold value is obtained as $0.0332 \mathrm{~V}$ in Fig. 10(f) for better identifying the variation trend in $P U_{S, C}$ for different rotor qualities.

Next, the 2-bar rotors with different porosity levels are tested at $2400 \mathrm{rpm}$. The waveforms and their corresponding spectra are shown in Fig. 11. The threshold value of $P U_{S, C}$ is indicated with the horizontal dash lines. As observed, $P U_{S, C}$ of the porosity rotor decreases by nearly 10 times compared with that of the healthy rotor. With the increase in porosity degree by drilling one more small hole on the rotor, $P U_{S, C}$ decreases from $0.0034 \mathrm{~V}$ to $0.0023 \mathrm{~V}$. Thus, the porosity fault and the fault level can be evaluated on the basis of the proposed $P U_{S, C}$ index with respect to the threshold.
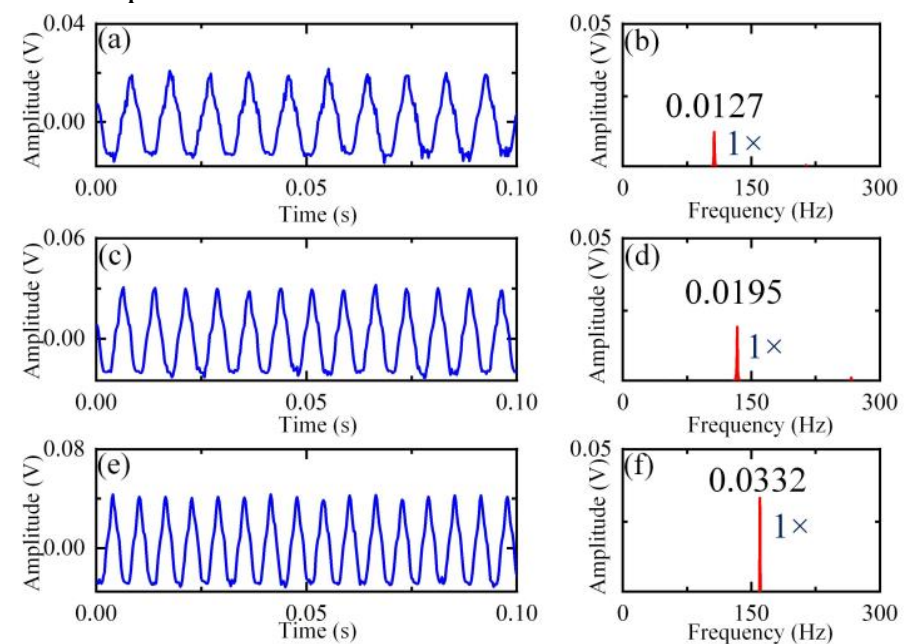

Fig. 10. Waveforms and spectra of 2-bar healthy rotors at different rotation speeds: (a) and (b) $1600 \mathrm{rpm}$, (c) and (d) $2000 \mathrm{rpm}$, (e) and (f) $2400 \mathrm{rpm}$.
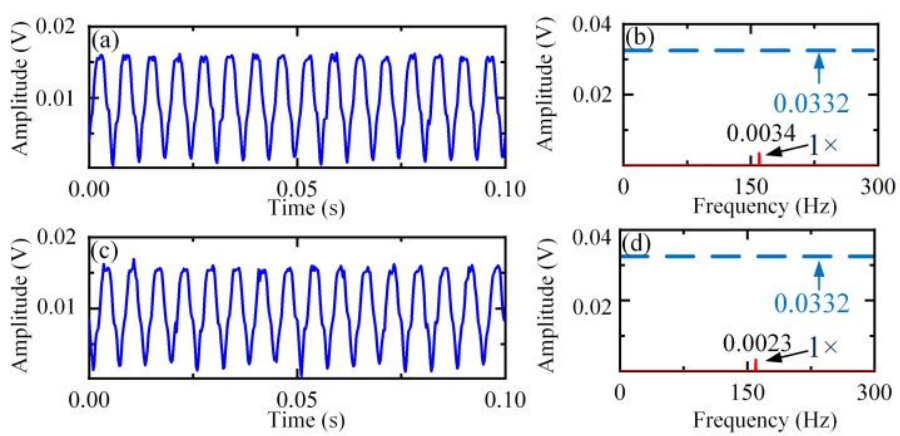

Fig. 11. Waveforms and spectra for the 2-bar porosity rotors with different fault levels: (a) and (b) low level of porosity, (c) and (d) high level of porosity.

\section{B. Evaluation of Broken Bar in a 4-bar Rotor}

In this subsection, the broken bar fault in a 4-bar rotor is evaluated using the proposed method. The heathy motor under different rotation speeds is tested first, and the results are shown in Fig. 12. Similar to the results in Fig. 10, the magnitude of $P U_{S, C}$ increases with the increase in rotation speed under the same DC voltage excitation. A comparison between Figs. 10(f) and 12(f) indicates that more rotor bars will also increase the magnitude of $P U_{S, C}$ for the same test condition. The threshold of $P U_{S, C}$ for the healthy motor is obtained as $0.0444 \mathrm{~V}$ at 2400 $\mathrm{rpm}$.

Next, a 4-bar rotor with a broken bar is tested under 2400 rpm, and the results are shown in Fig. 13. The spectrum of the induced voltage signal in Fig. 13(b) indicates that the magnitude of $P U_{S, C}$ is higher than that of the healthy motor. Such a result agrees with the theoretical analysis in Section III.D. The abovementioned porosity and broken bar experiments imply that the $P U_{S, C}$ value is a reliable QFI for discriminating these two kinds of faults and quantitatively evaluating the fault levels. The effectiveness and feasibility of the designed instrument and the proposed method have been validated on the simplified lab-manufactured rotors.
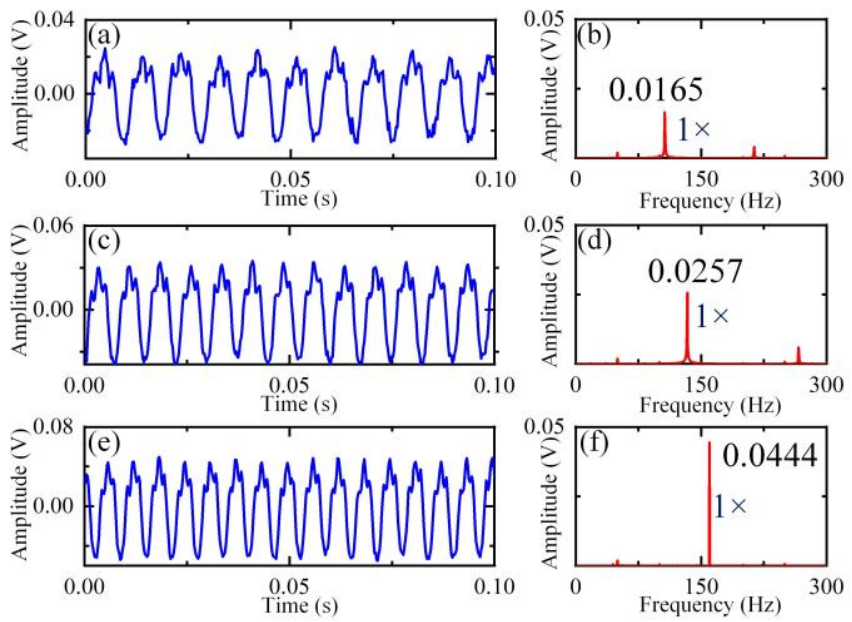

Fig. 12. Waveforms and spectra of 4-bar healthy rotors at different rotation speeds: (a) and (b) $1600 \mathrm{rpm}$, (c) and (d) $2000 \mathrm{rpm}$, (e) and (f) $2400 \mathrm{rpm}$.
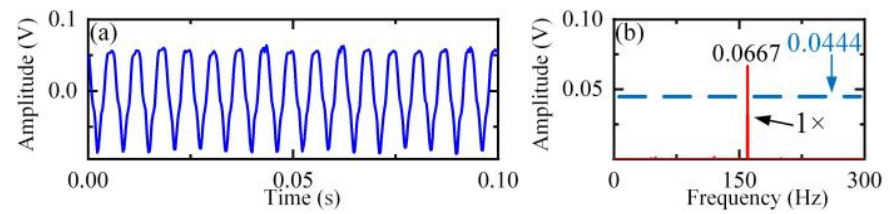

Fig. 13. (a) Waveform and (b) spectrum generated from the 4-bar rotor with a broken bar.

\section{Evaluation of Porosity and Broken Bar in a Practical 22-bar Rotor}

The 22-bar rotors disassembled from the SCIMs are tested to further verify the performance of the proposed method for practical rotors. The rotors with healthy, porosity, and broken bar conditions are shown in Fig. 9. The rotation speed is set as $3000 \mathrm{rpm}$, and the injected DC voltage is set as $30 \mathrm{~V}$. First, the waveform and spectrum of the healthy rotor are shown in Figs. 14(a) and 14(b), respectively. The threshold of $P U_{S, C}$ is obtained as $0.79 \mathrm{~V}$, as shown in Fig. 14(b). 

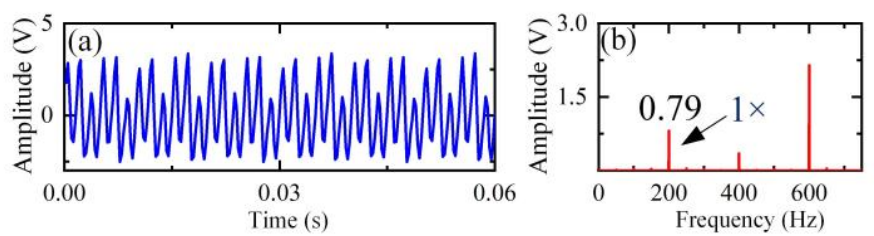

Fig. 14. (a) Waveform and (b) spectrum generated from the healthy 22-bar rotor.

Two rotors with different levels of porosity faults are tested and the results are shown in Fig. 15. As observed, the $P U_{S, C}$ values in Figs. 15(b) and 15(d) are lower than the threshold, as indicated by the horizontal dash lines. When the density of porosity increases, $P U_{S, C}$ further decreases. This tendency is similar to that of the 2-bar rotor in Fig. 11. Therefore, the proposed QFI is also suitable for inspecting and evaluating the porosity fault of the rotor with different bars.

The rotors with different levels of broken bars are then tested. The fault level is configured by drilling 1 to 4 holes at the rotor bar, as shown in Fig. 9. The time domain waveforms and the corresponding spectra of the rotors with different fault degrees are shown in Fig. 16. As observed, all the $P U_{S, C}$ values of the broken bar rotors are significantly higher than that of the healthy rotor. With the increase in the broken levels, $P U_{S, C}$ decreases from $4.10 \mathrm{~V}$ to $3.21 \mathrm{~V}$. Therefore, $P U_{S, C}$ can effectively evaluate the levels of the broken bars in a rotor.
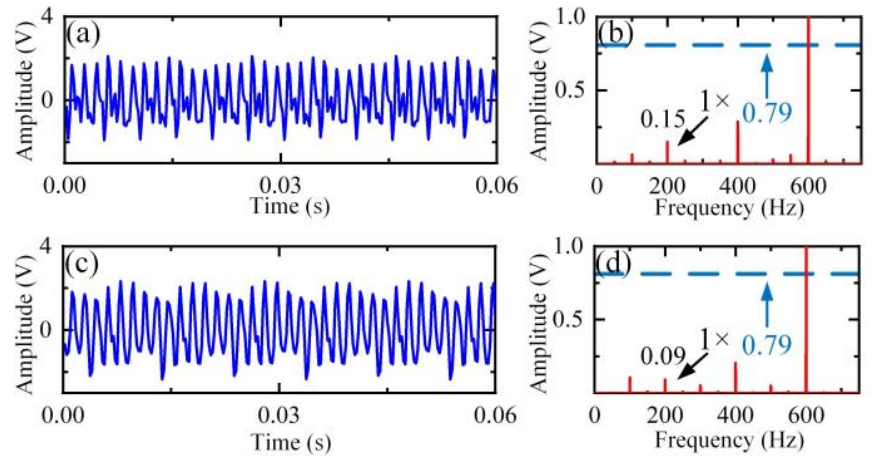

Fig. 15. Waveforms and spectra for the 22-bar porosity rotors with different fault levels: (a) and (b) low level of porosity, (c) and (d) high level of porosity.

In addition, the total processing time of data is as follows

$$
T=T_{1}+T_{2}
$$

where $T$ is the total processing time, $T_{1}$ is the data acquisition time, $T_{2}$ is the data calculation time. In this experiment, the designed instrument and its data acquisition system transmitted 10,000 points of collected data to the computer for in-situ rotor quality inspection. Considering that the sampling frequency is set at $4 \mathrm{kHz}$, the data acquisition time $T_{1}$ is $2.5 \mathrm{~s}$. The data calculation method is FFT that has a fast computing speed, which takes a few milliseconds. So that the calculation time $T_{2}$ can be negligible and the total processing time $T$ is $2.5 \mathrm{~s}$. Hence, the method proposed in this paper has high data processing efficiency and can achieve real-time rotor defect detection in the production line by introducing edge computing technology.

In summary, the designed instrument and the proposed method can accurately distinguish three typical healthy states of rotor: healthy, porosity, and broken bar. The fault levels of porosity and broken bar can also be quantitatively analyzed according to the variation trend of the $P U_{S, C}$ value with respect to the threshold. Furthermore, the designed instrument and its corresponding data processing system have fast computing speed and high processing efficiency, which can achieve real-time inspection. Thus, the proposed solution can be used for real-time rotor quality inspection in the production line, which will further improve the efficiency of rotor production.
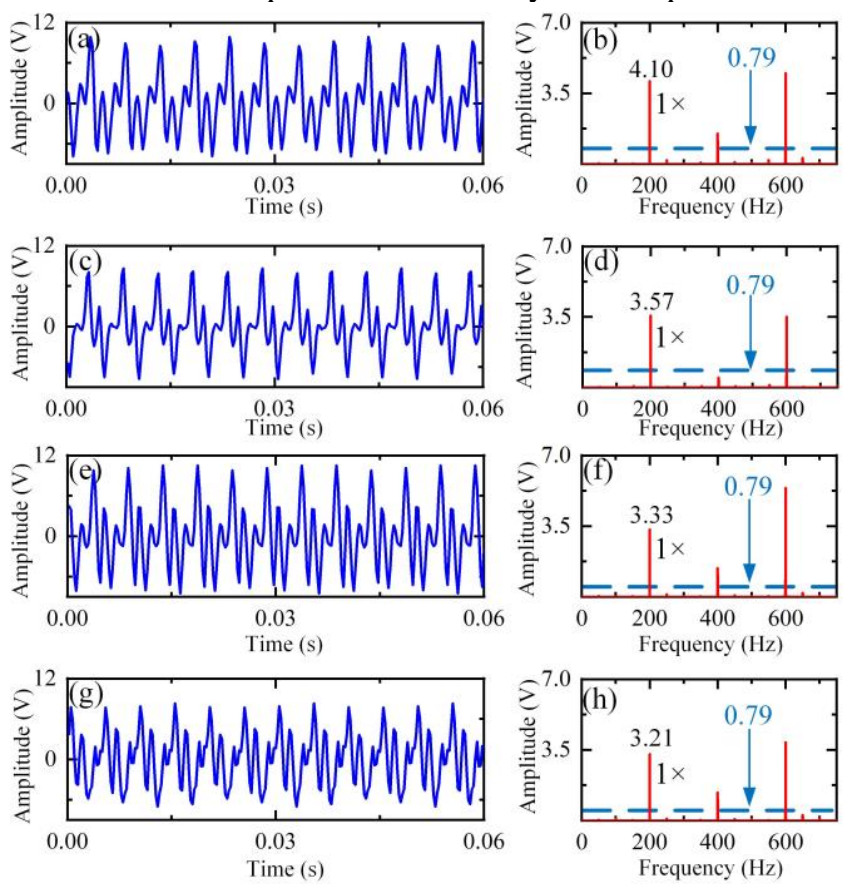

Fig. 16. Waveforms and spectra generated from the 22-bar rotors with different broken bar fault levels: (a) and (b) one drilled hole, (c) and (d) two drilled holes, (e) and (f) three drilled holes, (g) and (h) fourdrilled holes.

\section{Comparative Experiments}

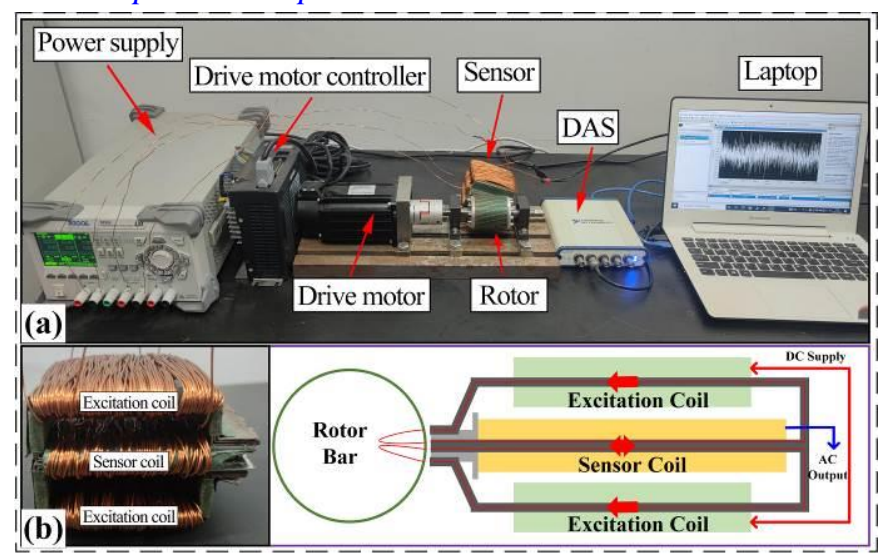

Fig. 17. (a) Experimental setup and (b) electromagnet sensor.

In order to validate the superiority of the proposed method, the rotor quality test (RQT) method proposed in Ref. [16] is used for comparison. The experimental setup for implementing the RQT method is shown in Fig. 17(a). The electromagnet sensor consists of two excitation coils and one sensor coil. The coils are wound on a steel framework as shown in the left panel of Fig. 17(b). The intensity of the generated magnetic field is adjusted by injecting a direct current. When the rotor is driven to rotate, the mutual induction induces a voltage in the sensor coil, as shown in the right panel of Fig. 17(b). The four 22-bar 
rotors with different broken bar fault levels are tested in the comparative experiments.

Since the parameters of the two instruments are different, an indicator Ind is proposed to compare the quantitative analysis performance as shown below

$$
\text { Ind }=\frac{F a u}{H e a}
$$

in which, Fau and $\mathrm{Hea}$ are the magnitudes of the fundamental frequencies of the faulty rotor and healthy rotor, respectively.

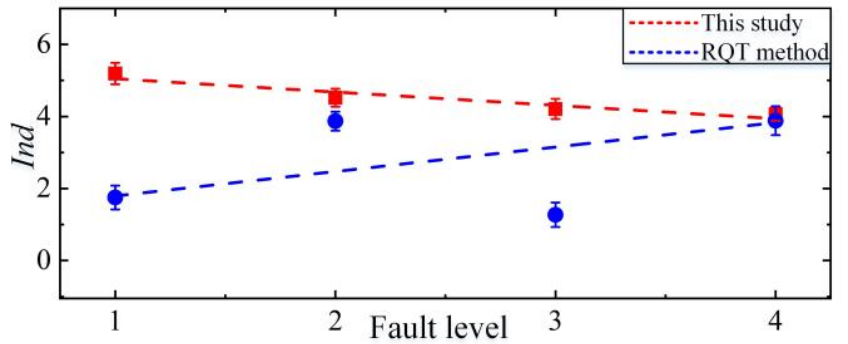

Fig. 18. Comparison results.

For each fault type of the rotor, 10 tests are conducted and the average Ind value is calculated. The results with error bars are shown in Fig. 18, it can be seen that the Ind values of the broken bar rotors are all larger than 1 for the two methods. Linear fitting is conducted to evaluate the quantitative relationship between the Ind value and the number of broken bars. The Ind value decreases with the increase of the number of the broken bars for the proposed method, and the $\mathrm{R}^{2}$ coefficient of fitting is 0.91. In comparison, the linear relationship is not obvious for the RQT method, and the $\mathrm{R}^{2}$ coefficient is 0.79 . Hence, the proposed method has a better performance for quantitative evaluation of broken levels.

\section{Discussions}

To make the proposed method more reliable in practical applications, the existing methods in literatures are listed and compared. Moreover, future works that might improve the performance of the methods are discussed.

\section{A. Comparison of Existing Methods}

A list of offline detection methods for rotor bar defects and their features are summarized in Table III. The ultrasound method in Ref. [28] can identify the location and size of the rotor faults. However, this method requires the equipment operator to have good professional knowledge, and it has low performance for detection of die cast rotor because of the characteristics of die cast process and the material. The rotor magnetic field analysis (RMFA) method in Ref. [29] used the permanent magnet based DC injection probe, which can detect major defects such as broken bar but lacks the study for detection of minor or distributed porosity rotors. The RQT method in Ref. [16] can accurately detect rotor bar defects but cannot quantitatively analyze the fault level as shown in Fig. 18 . The quality assurance testing (QAT) method for defective die cast rotors in Ref. [21] designed the electromagnetic flux sensor made by U-shaped permanent magnet and coil, which can detect die cast rotor defects well. But this method requires specially made sensors and has low convenience, which is not suitable for industrial applications. In contrast, the designed instrument can easily detect the rotor faults and also the rotor bar defects, and has potential applications in inspection of rotor quality in the production line.

TABLE III

ROTOR BAR DEFECT OFFLINE TEST METHODS

\begin{tabular}{ccccc}
\hline \hline Methods & $\begin{array}{c}\text { Die cast } \\
\text { rotor }\end{array}$ & $\begin{array}{c}\text { Minor } \\
\text { defect }\end{array}$ & $\begin{array}{c}\text { Quantitative } \\
\text { analyze }\end{array}$ & Convenience \\
\hline Ultrasound [28] & & $\checkmark$ & $\checkmark$ & \\
\hline RMFA [29] & $\checkmark$ & & $\checkmark$ & \\
\hline RQT [16] & $\checkmark$ & $\checkmark$ & & \\
\hline QAT [21] & $\checkmark$ & $\checkmark$ & $\checkmark$ & $\checkmark$ \\
\hline Proposed & $\checkmark$ & $\checkmark$ & $\checkmark$ & \\
\hline \hline
\end{tabular}

\section{B. Future Works}

The future works for improving the performance of this study are discussed as shown below. The proposed method focuses on single fault detection in single rotor bar. Namely, the porosity and broken bar fault are set on only one bar. In practice, the defects can occur in multiple rotor bars. Hence, the method should be improved to synchronously detect the defects in multiple bars.

The performance of the designed sensor can also be further improved. For example, an air-gap flux sensor with a narrow coil span can be installed in the stator to simultaneously record the flux signal [30]. The detection accuracy could be increased by fusing the induced voltage signal and flux signal.

This study detects the rotor defects in an offline mode before motor fabrication. A good-quality rotor installed on a motor would still be subjected to defects caused by degeneration after a long time of rotations. How to realize diagnosis and prognosis of rotor faults has been widely investigated in recent years [31]. Indeed, the useful life of the rotor is determined by its initial quality and the subsequent working conditions. This study can evaluate the initial quality condition of the rotor. It is meaningful to track the quality degeneration of the rotor in its span of life.

Besides the good detection performance, the algorithm of the proposed method has high efficiency. Benefiting from the rapid development of artificial intelligence technologies in industrial automation [32], the proposed method can be applied to the real-time inspection of SCIM rotor in a production line by exploiting the emerging edge computing technology.

\section{CONCLUSIONS}

This study designed a novel instrument and proposed an effective method for real-time defect detection of a die cast rotor in a SCIM in the production line. The instrument was remolded from a SCIM stator with three-phase windings. By injecting a DC voltage at phases $\mathrm{A}$ and $\mathrm{B}$ of the instrument, the induced voltage signal was generated from phase $\mathrm{C}$. According to this principle, the stator was transformed into an electromagnetic sensor. A QFI was constructed from the spectrum of the induced voltage signal to identify and evaluate the porosity and broken bar faults in the rotor. Theoretical analyses were conducted to characterize the variation trend of the proposed QFI under different rotor fault conditions. Three kinds of rotors including 2-, 4-, and 22-bar rotors were tested in 
experiments to validate the effectiveness and reliability of the designed instrument and proposed method. The experimental results agree with the theoretical results in discriminating and evaluating the porosity and broken bar faults. The designed instrument can be easily obtained from an industrial SCIM with low cost, and the proposed method is simple to implement and reliable for rotor quality inspection. The proposed method shows potential applications in real-time inspection of rotor quality in the production line.

\section{REFERENCES}

[1] S. A. Q. Mohammed, H. H. Choi, and J. -W. Jung, "Improved Iterative Learning Direct Torque Control for Torque Ripple Minimization of Surface-Mounted PMSM Drives," IEEE Trans. on Ind. Informat., Jan. 2021.

[2] J. Song, J. Zhao, F. Dong, J. Zhao, L. Xu, and Z. Yao, "A New Demagnetization Fault Recognition and Classification Method for DPMSLM," IEEE Trans. on Ind. Informat., vol. 16, no. 3, pp. 1559-1570, Mar. 2020.

[3] I. Zamudio-Ramirez, R. A. A. Osornio-Rios, J. A. Antonino-Daviu, H. Razik, and R. d. J. Romero-Troncoso, "Magnetic Flux Analysis for the Condition Monitoring of Electric Machines A Review," IEEE Trans. on Ind. Informat., Apr. 2021.

[4] A. Bruno, M. Caruso, A. O. D. Tommaso, R. Miceli, C. Nevoloso, and F. Viola, "Simple and Flexible Power Loss Minimizer With Low-Cost MCU Implementation for High-Efficiency Three-Phase Induction Motor Drives," IEEE Trans. on Ind. Appl., vol. 57, no. 2, pp. 1472-1481, Mar.-Apr. 2021.

[5] J. Yun, S. Lee, M. Jeong, and S. B. Lee, "Influence of Die-Cast Rotor Fill Factor on the Starting Performance of Induction Machines," IEEE Trans. on Magn., vol. 54, no. 3, pp. 1-4, Mar. 2018.

[6] J. Yun and S. B. Lee, "Influence of Aluminum Die-Cast Rotor Porosity on the Efficiency of Induction Machines," IEEE Trans. on Magn., vol. 54, no. 11, pp. 1-5, Nov. 2018.

[7] S. T. Varghese, B. Singh, and K. R. Rajagopal, "Fault Investigations on Die-Cast Copper Rotors," IEEE Trans. on Ind. Appl., vol. 54, no. 1, pp. 184-194, Jan.-Feb. 2018

[8] P. S. B. and H. S., "Rational-Dilation Wavelet Transform Based Torque Estimation from Acoustic Signals for Fault Diagnosis in a Three-Phase Induction Motor," IEEE Trans. on Ind. Informat., vol. 15, no. 6, pp. 3492-3501, Jun. 2019.

[9] M. S. Rafaq, M. Faizan Shaikh, Y. Park, and S. B. Lee, "Reliable Airgap Search Coil based Detection of Induction Motor Rotor Faults under False Negative MCSA Indications," IEEE Trans. on Ind. Informat., Dec. 2020.

[10] P. Karvelis, G. Georgoulas, I. P. Tsoumas, J. A. Antonino-Daviu, V. Climente-Alarcón, and C. D. Stylios, "A Symbolic Representation Approach for the Diagnosis of Broken Rotor Bars in Induction Motors," IEEE Trans. on Ind. Informat., vol. 11, no. 5, pp. 1028-1037, Oct. 2015.

[11] S. Singh and N. Kumar, "Detection of Bearing Faults in Mechanical Systems Using Stator Current Monitoring," IEEE Trans. on Ind. Informat., vol. 13, no. 3, pp. 1341-1349, Jun. 2017.

[12] G. H. Bazan, P. R. Scalassara, and A. Goedtel, "Information Theoretical Measurements From Induction Motors Under Several Load and Voltage Conditions for Bearing Faults Classification," IEEE Trans. on Ind. Informat., vol. 16, no. 6, pp. 3640-3650, Jun. 2020.

[13] J. Faiz, V. Ghorbanian, and B. M. Ebrahimi, "EMD-Based Analysis of Industrial Induction Motors With Broken Rotor Bars for Identification of Operating Point at Different Supply Modes," IEEE Trans. on Ind. Informat., vol. 10, no. 2, pp.957-966, May 2014.

[14] R. de Jesus Romero-Troncoso, "Multirate Signal Processing to Improve FFT-Based Analysis for Detecting Faults in Induction Motors," IEEE Trans. on Ind. Informat., vol. 13, no. 3, pp. 1291-1300, Jun. 2017.

[15] S. W. Clark and D. Stevens, "Induction Motor Rotor Bar Damage Evaluation With Magnetic Field Analysis," IEEE Trans. on Ind. Appl., vol. 52, no. 2, pp. 1469-1476, Mar.-Apr. 2016.

[16] S. T. Varghese, K. R. Rajagopal, and B. Singh, "Design and Development of Rotor Quality Test System for Die-Cast Copper Rotors," IEEE Trans. on Ind. Appl., vol. 54, no. 3, pp. 2105-2114, May-Jun. 2018.

[17] A. Ceban, R. Pusca, and R. Romary, "Study of Rotor Faults in Induction Motors Using External Magnetic Field Analysis," IEEE Trans. on Ind. Electron., vol. 59, no. 5, pp. 2082-2093, May 2012.
[18] Z. Hosseinpoor, M. M. Arefi, R. Razavi-Far, N. Mozafari, and S. Hazba vi, "VirtualSensors for Fault Diagnosis: ACase of Induction Motor Broken Rotor Bar," IEEE Sensors J., vol. 21, no. 4, pp. 5044-5051, Feb. 2021.

[19] C. G. Dias and F. H. Pereira, "B roken Rotor Bars Detection in Induction Motors Running at Very Low Slip Using a Hall Effect Sensor," IEEE Sensors J., vol. 18, no. 11, pp. 4602-4613, Jun. 2018.

[20] M. Nemec, K. Drobnic, D. Nedeljkovic, R. Fiser, and V. Ambrozic, "Detection of Broken Bars in Induction Motor Through the Analysis of Supply Voltage Modulation," IEEE Trans. on Ind. Electron., vol. 57, no. 8, pp. 2879-2888, Aug. 2010.

[21] M. Jeong, J. Yun, Y. Park, S. B. Lee, and K. N. Gyftakis, "Quality Assurance Testing for Screening Defective Aluminum Die-Cast Rotors of Squirrel Cage Induction Machines," IEEE Trans on Ind. Appl., vol. 54, no. 3, pp. 2246-2254, May-Jun. 2018.

[22] B. Tian, Q. An, J. Duan, D. Sun, L. Sun, and D. Semenov, "Decoupled Modeling and Nonlinear Speed Control for Five-Phase PM Motor Under Single-Phase Open Fault," IEEE Trans. on Power Electron., vol. 32, no. 7, pp. 5473-5486, Jul. 2017.

[23] M. Ikeda and T. Hiyama, "Simulation Studies of the Transients of Squirrel-Cage Induction Motors," IEEE Trans. on Energy Convers., vol. 22, no. 2, pp. 233-239, Jun. 2007.

[24] J. Martinez, A. Belahcen, and A. Muetze, "Analysis of the Vibration Magnitude of an Induction Motor With Different Numbers of Broken Bars," IEEE Trans. on Ind. Appl., vol. 53, no. 3, pp. 2711-2720, May-Jun. 2017.

[25] A. C. Smith, R. C. Healey, and S. Williamson, "A transient induction motor model including saturation and deep bar effect," IEEE Trans. on Energy Convers., vol. 11, no. 1, pp. 8-15, Mar. 1996.

[26] Y. Soleimani, S. M. A. Cruz, and F. Haghjoo, "Broken Rotor Bar Detection in Induction Motors Based on Air-Gap Rotational Magnetic Field Measurement," IEEE Trans. on Instrum. and Meas., vol. 68, no. 8, pp. 2916-2925, Aug. 2019.

[27] R.F. Walliser and C. F. Landy, "Determination of interbar current effects in the detection of broken rotor bars in squirrel cage induction motors," IEEE Trans. on Energy Convers., vol. 9, no. 1, pp. 152-158, Mar. 1994.

[28] S. L. Nau, D. Schmitz, and W. de Lima Pires, "Methods to evaluate the quality of stator and rotor of electric motors," in IEEE 10th Int. Symp. on Diagn. for Elect. Mach, Power Electron. and Drives (SDEMPED), pp. 64-70, 2015.

[29] S. W. Clark and D. Stevens, "Squirrel cage induction motor cast rotor defect detection with magnetic field analysis," in Proc. 18th int. Conf. Elect. Mach. Syst. (ICEM), pp. 1019-1023, Oct. 2015.

[30] A. Mohammed, J. I. Melecio, and S. Djurović, "Electrical Machine Permanent Magnets Health Monitoring and Diagnosis Using an Air-Gap Magnetic Sensor," IEEE Sensors J., vol. 20, no. 10, pp. 5251-5259, May 2020.

[31] R. Kizito, P. Scruggs, X. Li, M. Devinney, J. Jansen, and R. Kress, "Long Short-Term Memory Networks for Facility Infrastructure Failure and Remaining Useful Life Prediction," IEEE Access, vol. 9, pp. 67585-67594, 2021.

[32] G. Qian, S. Lu, D. Pan, H. Tang, Y. Liu, and Q. Wang, "Edge Computing: A Promising Framework for Real-Time Fault Diagnosis and Dynamic Control of Rotating Machines Using Multi-Sensor Data," IEEE Sensors J., vol. 19, no. 11, pp. 4211-4220, Jun. 2019. 